\title{
Heat Transfer and Aerodynamics Studies of Multiple Cooling Holes
}

\author{
Kamil Abdullah ${ }^{1,2}$, Onodera Hisato ${ }^{1}$, Funazaki Ken-ichi ${ }^{1}$ and Ideta Takeomi ${ }^{3}$ \\ ${ }^{1}$ Department of Mechanical Engineering, Iwate University, \\ 3-5 Ueda, Morioka-shi, Iwate 030-8551, JAPAN \\ ${ }^{2}$ Universiti Tun Hussein Onn Malaysia, MALAYSIA \\ ${ }^{3}$ IHI Corporation, JAPAN
}

\begin{abstract}
This paper presents a heat transfer and details flowfield measurements of multiple cooling holes. Normal cylindrical hole with steeper inclined angle of $20^{\circ}$ arranged to perform a 5 times 4 cooling holes matrix have been considered. Experiments have been done at a single Reynolds number base on the hole diameter equal to 6200 at three blowing ratios of $0.5,1.0$ and 2.0 for the heat transfer and only for the later two for aerodynamics measurements. The heat transfer experiments involved the IR camera to capture the surface temperature data while the aerodynamics experiments involved the three dimensional Laser Doppler Velocimeter for velocity measurements. Results of heat transfer consists of overall film cooling effectiveness distribution and laterally average film cooling effectiveness in $x$-direction represented by a contour plot and a graph respectively. Four measurement planes have been considered in the aerodynamics experiments which are located at $x / \mathrm{D}=7,17,27$ and 37 . The aerodynamics results presented in this paper include of various contour plots which represent the distribution of normalize velocity for $u, v$, and $w$ components, normalize root mean square velocity for $u, v$, and $w$ components and the Reynolds stress tensor. Both set of results have been discussed in such, a clear relation between the flow behavior and heat transfer phenomena have been established.
\end{abstract}

\section{INTRODUCTION}

Thermal efficiency of a gas turbine can unswervingly improved by means of higher turbine inlet temperature. Most of the modern gas turbines are now operating at a very high temperature exceeding the allowable material temperature. Cooling techniques of turbine components are compulsory to allow such operating condition and has become one of the essential aspects in gas turbine system design. Among all the cooling techniques applicable, film cooling has been a common feature in modern gas turbine. It intends to protect the blade surface from having a direct contact with the hot gases which is achieved by injecting the coolant fluid through the blade surface into the external boundary layer. The injected cold air will form a buffer layer of relatively cool air between the surface and the hot gases contained within the turbine flow path.

The film cooling techniques have been studied for more than 30 years. A general review has been given by Goldstein [1] on flat plate surface film cooling studies prior to 1971. Presented in the paper were the effects of various geometries and flow parameters that dictate the film cooling performance. Extensive works have been done to improve the film cooling performance ever since and

Presented at International Gas Turbine Congress 2011 Osaka, November 13-18, Osaka, Japan, IGTC2011-0057

Review completed February 7, 2012 only a brief review is provided in this paper. Inclined film cooling holes have shown significant improvement over perpendicular cooling hole by allowing more coolant to remain attached to the surface [2-4]. Although further reduction on the hole angle is expected to produce better film cooling performance, most of the available literatures have been employing hole angle of $35^{\circ}$ or $30^{\circ}$ with the later prove to provide better cooling performance. One of the reasons for not to have steeper hole angle is due to the manufacturing difficulties of it.

To provide continuous coverage of the coolant on the surface, the cooling holes can be arranged in various patterns. Ligrani et al. $[5,6]$ presented a film cooling effectiveness of a two row cooling holes at three different pattern. It was concluded that the two row cooling holes can significantly increase the laterally average cooling effectiveness either arranged in-line or staggered with the later producing superior results. The physical explanation on the significant improvement of film cooling effectiveness is due to rejuvenation of the coolant as a fresh coolant were introduce by the downstream holes. Given the cooling capability of the first row coolant is not yet totally vanished, the newly introduce coolant will have a better cooling capability from the coolant introduced by the upperstream hole.

In addition to the hole geometries and arrangements, the amount of coolant injected through the cooling hole is also an important variable that decide the film cooling performance. The amount of coolant injected typically presented by blowing ratio with too low blowing ratio will not provide enough coverage of the surface while excessive coolant flowrate can result-in the lift-off of the coolant from the surface thus leave it unprotected. Considerable amount of investigations have been done to justify the effects of blowing ratio to film cooling performance. To name one of the latest similar studies is Rabekah et al. [7]. The paper presented the effect of various blowing ratio to the film cooling performance with the wall temperature data were obtained by using temperature and pressure sensitive paints. The study shows the film cooling effectiveness is significantly influence by the blowing ratio which is generally agreed by previous available findings [2-4, 8, 9]. As been mentioned above most of the explanation of film cooling performance closely related the flow behavior for a given hole geometry, arrangement and flow condition. Therefore investigation on the flow behavior in the film cooling system is imperative.

The aerodynamics investigations on film cooling have given some physical insight to the principal flow structure dictating the interaction between the mainstream and secondary air jet hence giving physical interpretation of a given film cooling performance. Given the important of the flow behavior, the aerodynamics investigations on film cooling have started as early as 1980's. Although, the aerodynamics studies on film cooling have started quite a long 
time ago, there are still relatively huge void to be fill-up compared to the available heat transfer results up to the date. The kidney vortices as the prominent flow structure downstream of film cooling hole have been identified empirically by previous research [10-12], which concluded that the pair vortices entrain the mainstream fluid and transport it towards the blade surface. Pietrzyk et al. [12] in his work also found the separation region to occur at the hole entrance of the leeward side of the hole. In the study, the coolant was supplied by a plenum and as a result encounter large turning angle at the hole leeward side thus skewed the exiting jet to the windward side of the hole. The aerodynamics studies of film cooling have then given a new breath with the introduction of the laser base measurement instruments namely PIV and LDV. Thole et al. [13] have used LDV to investigate the flowfield for expanded exit cooling hole with comparison to the normal cylindrical hole. Centre line velocity profile and contour plot of the flowfield downstream of the cooling hole was presented in the paper. Prediction on the film cooling performance have been made base on the interpretation of the measured flowfield. Film cooling performance of similar hole geometries which have been published later by Gritsch et al. [14]. Good physical insight has been established between the aerodynamics and heat transfer results. Thole et al. [13] also highlighted the important of understanding the inside hole flowfield as the hole exit flowfield is expected to plays major role on the formation of the downstream flowfield of the cooling hole.

On the hand, Wright et al. [15] have presented the effect of mainstream turbulent intensity level to the film cooling flow structure. The flowfield data have been measured by using PIV on the plane normal to lateral direction to reflect the previous heat transfer study using the identical hole geometry. It was concluded that the main reason behind poorer film cooling performance at higher turbulent level is due to the enhancement of the mixing between the coolant and the primary air which lead to coolant temperature drop of the thus reducing the its cooling capacity. Kampe et al. [16] in his paper presented a complete study of diffuser shape film cooling holes covering both the heat transfer and the aerodynamics aspects. The heat transfer measurements have been made by IR camera while both PIV and LDV have been used in the aerodynamics measurements. The paper also presenting a CFD results of the considered experimental condition. Physical interpretation on the film cooling performance have been made base on the aerodynamics results. Given a good agreement between the experimental and the CFD have also been presented; the paper has provided an inclusive review of the diffuser shape film cooling holes.

The present study focuses on evaluating the performance of simple cylindrical hole with steeper angle at $20^{\circ}$. With the commonly applied hole angle at $30^{\circ}$ and $35^{\circ}$, the geometry of the cooling hole considered in the present study can be considered as one of its novelty. In addition to that, multiple cooling holes arranged to perform five in-line rows of cooling holes can also be considered as novelty features of this study with most of the available literature only focusing on a single row of cooling holes. Another special feature of the present study is the presented results which combined the film cooling effectiveness and details three dimensional flowfield downstream of the cooling holes.

\section{EXPERIMENTS}

The experiments discussed in this paper involve two different experimental setups, each for the heat transfer and aerodynamic measurements. As both of these setups involved two different wind tunnels, two different experimental setups have been erected with the size of each test section made to be compatible to the dimension of the respective wind tunnel. To enable direct complementation between the heat transfer and the aerodynamics results, the test model have been designed to have the same non-dimensional configuration which will further discuss in the next section. Experiments have been done at targeted Reynolds number base on the hole diameter, $\mathrm{Re}_{\mathrm{D}}=6200$ at three different blowing ratio, $\mathrm{BR}=0.5$, 1.0 and 2.0 for the heat transfer and only the later two BR have been consider for the aerodynamic experiments. Details of the experimental condition are given in Table 1 .

Table. 1 Details on the experimental condition

\begin{tabular}{|c|c|c|c|c|c|c|}
\hline & \multicolumn{2}{|c|}{ Targeted } & \multicolumn{4}{|c|}{ Actual } \\
\hline & $\mathrm{Re}_{\mathrm{D}}$ & $\mathrm{BR}$ & $\mathrm{Re}_{\mathrm{D}}$ & $\mathrm{BR}$ & $\mathrm{T}_{\infty},\left({ }^{\circ} \mathrm{C}\right)$ & $\mathrm{T}_{\mathrm{c}},\left({ }^{\circ} \mathrm{C}\right)$ \\
\hline \multirow{3}{*}{$\begin{array}{c}\text { Heat } \\
\text { Transfer }\end{array}$} & \multirow{5}{*}{ 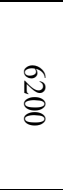 } & 0.5 & 6208 & 0.51 & 27.0 & 56.7 \\
\hline & & 1.0 & 6202 & 1.01 & 27.4 & 57.4 \\
\hline & & 2.0 & 6213 & 2.01 & 28.2 & 58.2 \\
\hline \multirow{2}{*}{$\begin{array}{c}\text { Aerody- } \\
\text { namics }\end{array}$} & & 1.0 & 6222 & 1.00 & 10.5 & 20.1 \\
\hline & & 2.0 & 6201 & 2.00 & 7.0 & 17.0 \\
\hline
\end{tabular}

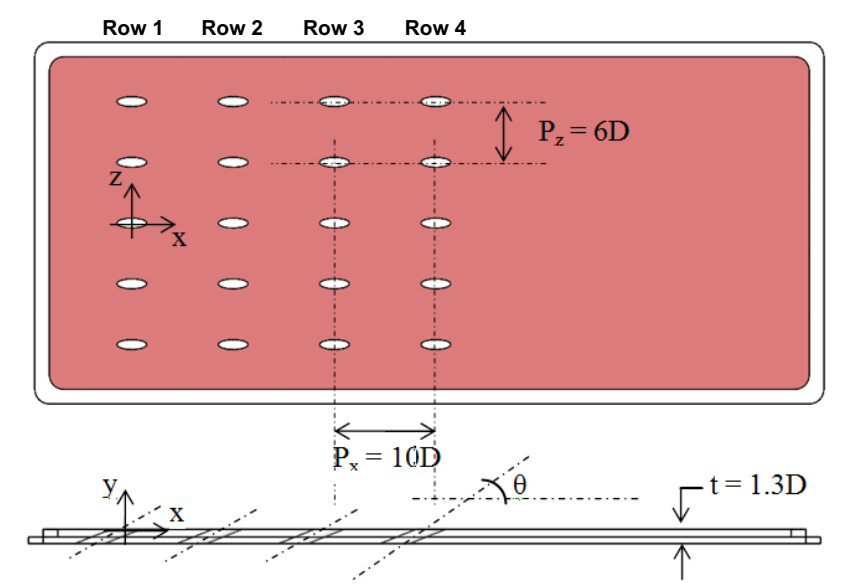

Fig. 1 Holes configuration of the test model

\section{Test Model}

Test model considered in the present paper has a total number of 20 cooling holes arranged in 5 times 4 matrix as shown in Figure 1. The figure also shows the shared non-dimensional configuration of the hole for both, heat transfer and aerodynamics study. The cooling hole employed is a normal cylindrical hole with inclination angle, $\theta=20^{\circ}$. The hole diameter for the heat transfer and aerodynamics studies is set to be at $7 \mathrm{~mm}$ and $10 \mathrm{~mm}$ respectively. The thickness of the test plate was designed to provide the hole length to diameter ratio, $l / \mathrm{D}=6$. The test models were made from acrylic plate with the manufacturing precision of $\pm 0.1 \mathrm{~mm}$. Black paint has been applied on the test model surface to represent the black body in the heat transfer experiments and to reduce the surrounding noise during the aerodynamics measurement cause by laser reflection. Table 2 provides complete dimension of the test models involved in the present study.

Table.2 Details dimension of the test models

\begin{tabular}{|l|c|c|}
\cline { 2 - 3 } \multicolumn{1}{c|}{} & Heat Transfer & Aerodynamic \\
\hline Hole diameter, $\mathrm{D}(\mathrm{mm})$ & 7 & 10 \\
\hline Hole angle, $\theta\left({ }^{\circ}\right)$ & 20 & 20 \\
\hline Thickness, $\mathrm{t}(\mathrm{mm})$ & 9.1 & 13 \\
\hline Spanwise pitch, $\mathrm{P}_{\mathrm{z}}(\mathrm{mm})$ & 42 & 60 \\
\hline Streamwise pitch, $\mathrm{P}_{\mathrm{x}}(\mathrm{mm})$ & 70 & 100 \\
\hline
\end{tabular}

\section{Heat Transfer Experiment}

The simplified view of the experimental setup is shown in Figure 2. The facility consists of a wind tunnel used to supply the mainstream air and a separate blower to supply the secondary air. The test duct cross section was designed to have $450 \mathrm{~mm}$ width and $280 \mathrm{~mm}$ height with a sharp upperstream edge end to recreate the boundary layer inside the test section. The overall size of the test model for the heat transfer experiment is set to be at $250 \mathrm{~mm} \mathrm{x}$ $545 \mathrm{~mm}$ with the hole diameter of $7 \mathrm{~mm}$. The size of the test model have taken into consideration the possible development of film 
cooling effectiveness region further downstream of the last row of the cooling holes. Details of other dimension of the test plate can be found in Table 2. For the purpose of IR camera measurement, a window has been made on the front plate of the test duct. The window is covered by stretch polyurethane sheet in order to provide a penetrable layer of IR wave that going to be emitted by the test plate during the measurement. The sheet is at $0.2 \mathrm{~mm}$ thickness; thin enough to cause very little effect on IR transmissivity. The use of such materials as the measurement window has been presented by Ekkad et al. [17]. Similar to the previous studies [17], thermocouples have been place on the test model to provide temperature data for the calibration purpose which will be used to estimate the emissivity of the test surface. Location of the IR camera and the measurement window involved in the experimental setup is shown in Figure 2. The IR camera engaged is a NEC/Avio H2640 with maximum recording capability of 30 frames per second. The camera also has a spectral range 3 to $8 \mu \mathrm{m}$ which enable the normal measured temperature range between $-20^{\circ} \mathrm{C}$ and $60{ }^{\circ} \mathrm{C}$.

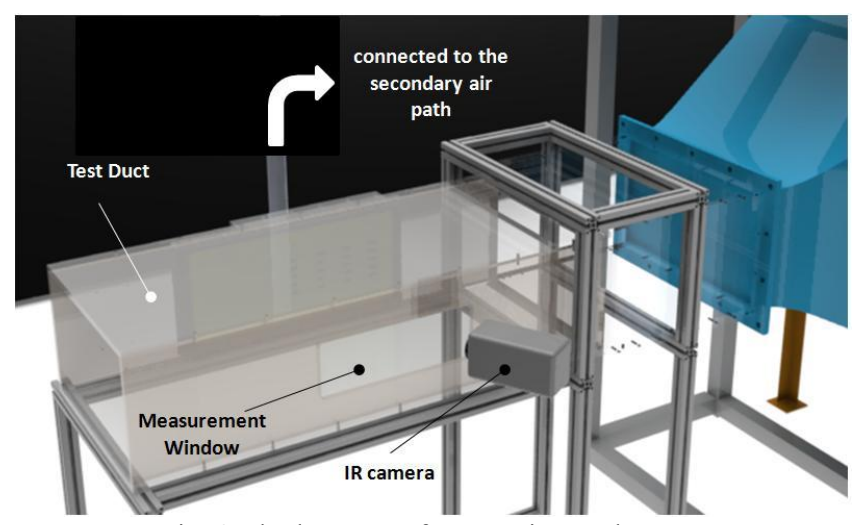

Fig. 2 The heat transfer experimental setup

The secondary air was supplied from a secondary blower equipped with an inverter which enables direct control of the blower rotational speed which determined by the supplied mass flowrate during the experiments. From the blower the air will go through a laminar flow meter before entering the heater to be heated-up to the designated temperature. The laminar flow meter is attached to a digital pressure transducer to verify the supplied mass flowrate three-way pneumatic valve was installed on the secondary air flow path between the heater and the secondary air chamber to control the flow of the secondary air whether to be supplied into the chamber or to be release to the surrounding.

At the start of the experiments, the secondary air will be released to the surrounding while it is heated. Just after the air reach the designated temperature, IR camera will be switch to the recording mode and the pneumatic valve will be activated to change the path of the secondary air into the chamber which later on will penetrates into the mainstream through the cooling holes. The IR images containing the temperature data will be continuously captured until the inside chamber temperature becomes stagnant (steady-state). The recorded data will be later be used for the heat transfer analysis explained in the next section.

\section{Heat Transfer Analysis}

The performance of a film cooling technique commonly measured by means of non-dimensionless temperature as given in Eq. 1 with $T_{w}, T_{\infty}$ and $T_{c}$ are wall temperature, mainstream temperature and secondary air temperature respectively. This variable is also generally known as the film cooling effectiveness.

$$
\eta=\frac{T_{\infty}-T_{w}}{T_{\infty}-T_{c}}
$$

As $\mathrm{T}_{\infty}$ and $\mathrm{T}_{\mathrm{c}}$ can be directly obtained by thermocouples during the experiments, the wall temperature data in the other hand will be produced by the IR camera. To have an accurate wall temperature data, the temperature data generated by the IR camera will first go through a correction process based on measured wall temperature by the thermocouple before being used to determine the film cooling effectiveness.

\section{Aerodynamics Experiment}

The aerodynamics measurements presented in this paper have been done on a relatively high capacity close circuit wind tunnel with the outlet size of $800 \mathrm{mmx} 800 \mathrm{~mm}$. A transition duct has been placed to reduce the outlet area to $640 \mathrm{~mm} \times 300 \mathrm{~mm}$ which suited the test duct size at $620 \mathrm{~mm} \times 260 \mathrm{~mm}$ inlet dimension with $1550 \mathrm{~mm}$ length. The view of the test duct together with the position of the laser probe involved in the measurement is shown in Figure3. The orientation of the test duct made the test model surface to be perpendicular to the ground level. Such orientation is necessary to enable the Laser Doppler Velocimeter (LDV) probe to access the desired measurement location. The secondary air was supplied through a separate blower equipped with a laminar flow meter. After passes the laminar flow meter, the secondary air will enter a secondary air chamber before being introduced into the mainstream flow through the cooling hole.

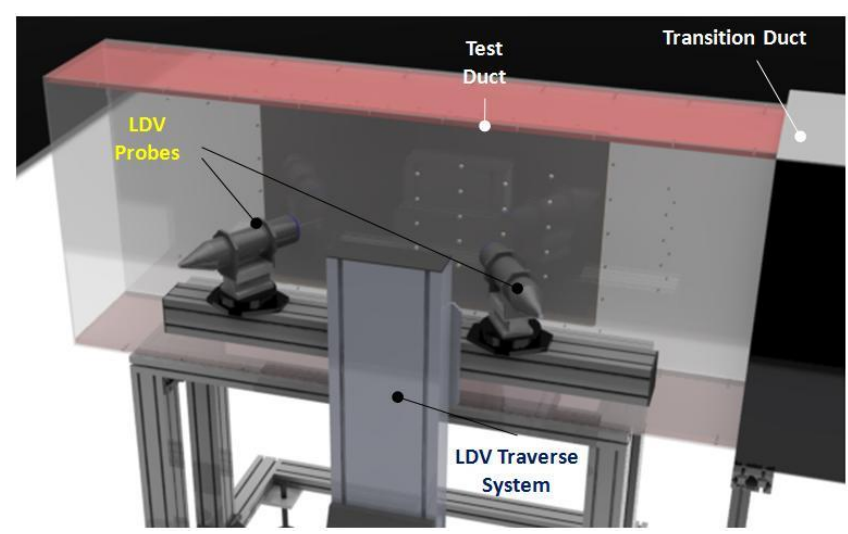

Fig. 3 The aerodynamics experimental setup

A three-component, coincident, fiber optic Laser Doppler Velocimeter (LDV) was used to measure the velocity fields. The commercial LDV system was an $85 \mathrm{~mm}$ fiber optic probe from Dantec. The laser beam is set to have a diameter of $2 \mathrm{~mm}$ with a focal length of $400 \mathrm{~mm}$. The probes where aligned to inclined at $25^{\circ}$ from the centre line to upperstream and downstream direction as shown in Figure 3. As the result of the alignment, the measured velocities will need to go through a transformation process to represent the actual experimental axis. The transformation and other data analyses were done through BSA Flow Software supplied together with the processor; Dantec's BS F60 Processor and 3-D Traversing System by Dantec. Both the primary and secondary air was seeded with fog generated by the fog generator. A fog tank has been used to enable continuous supply of the fog during the experiments.

The velocities were measured at four different plane locations, $\mathrm{x} / \mathrm{D}=7.0,17.0,27.0$ and 37.0. The plane size has been decided base on the preliminary measurements prior the actual measurements with intention avoiding insignificant area to be involved in the later measurements. The measurement grid size applied on the plane is set to be $2 \mathrm{~mm} \times 2 \mathrm{~mm}$ which have also been prove to be small enough to capture the flow details during the preliminary measurements.

\section{Aerodynamics Analysis}

The interference of the seeding particle inside the created laser volume enables the laser to obtain a feedback which is interpreted as velocity component, $u, v$, and $w$ in $x$-direction, $y$ - direction and $z$-direction respectively. The velocity components were estimated based on the statistical data of the seeding particle that get intact 
with the laser volume. The numbers of counts involved during the measurement set to be minimum at 750 counts with almost all the considered measurement points recording counts value above 2000 . Eq. 2, shows the formulation in determining the velocity components with $N$ is the total numbers of counts involved and $i$ is the respective velocity at a given counts.

$$
\bar{U}_{x, y, z}=\frac{1}{N} \sum_{i=1}^{N} U_{i}
$$

The root mean square (RMS) value of each velocity component can also be determined from the available counts data which is described in Eq. 3.

$$
U-R M S_{x, y, z}=\sqrt{\frac{1}{N-1} \sum_{i=1}^{N}\left(U_{i}-\bar{U}_{x, y, z}\right)^{2}}
$$

In addition to the above mentioned variables, the value of Reynolds stress tensor can also be generated from the measured LDV data which is determine by Eq. 4 and Eq. 5. Both of the mentioned Reynolds stress tensor components have also been included in the present study.

$$
\begin{aligned}
& \overline{u^{\prime} v^{\prime}}=\frac{1}{N} \sum_{i=1}^{N}\left(u_{i}-\bar{u}\right)\left(v_{i}-\bar{v}\right) \\
& \overline{u^{\prime} w^{\prime}}=\frac{1}{N} \sum_{i=1}^{N}\left(u_{i}-\bar{u}\right)\left(w_{i}-\bar{w}\right)
\end{aligned}
$$

\section{Measurement Uncertainties}

The mainstream temperature uncertainty of the heat transfer measurement was recorded to be at $0.25 \%$ or $\pm 0.08 \mathrm{~K}$ with the secondary air temperature uncertainty recorded to be at $0.17 \%$ equivalent to $\pm 0.06 \mathrm{~K}$. The highest temperature uncertainty is recorded by the measured temperature of the IR camera which is at $0.38 \%$ equivalent to $\pm 0.13 \mathrm{~K}$. The high uncertainty of the IR camera measured temperature could be contributed by the employment of stretch polyurethane as a measurement window.

For the aerodynamics measurements, the measurement uncertainties are mainly focus on the LDV velocity measurement itself. Based on $95 \%$ confidence interval, the uncertainty of the freestream velocity is calculated to be at $1.4 \%$, while the maximum velocity uncertainty inside the shear layer is recorded to be at $5.6 \%$. Elsewhere, the positioning of the LDV probe volume with respect to the hole position for all axis were at $\Delta x= \pm 0.01 \mathrm{~mm}, \Delta y= \pm 0.01 \mathrm{~mm}$ and $\Delta \mathrm{z}= \pm 0.01 \mathrm{~mm}$.

\section{RESULTS AND DISCUSSIONS}

The presentation and discussion of the results involved in the present study will be separated into two sections; the heat transfer and aerodynamics. In heat transfer section, verification of the current heat transfer setup and procedure is made with comparison to previous results. Figures showing the overall film cooling effectiveness distribution are presented together with the laterally average film cooling effectiveness distribution along the $x / \mathrm{D}$ distance. As for the aerodynamics results, variables such as normalize velocity component of $u, v$, and $w$, normalize RMS velocity components of $u, v$, and $w$ and Reynolds stress tensor of $\overline{u^{\prime} v^{\prime}}$ and $\overline{u^{\prime} w^{\prime}}$ are presented. The normalize variables have been using one single reference value which is the main stream velocity for the associated cases. All the results are presented in a 2D contour plot at all four measurement planes, $x / \mathrm{D}=7,17,27$ and 37 for all experimental conditions. Although the results presented in two different sections, the discussion involved some interaction between the two sections as the author aim to build the connection between the heat transfer and the aerodynamics.
Heat Transfer

To validate the present heat transfer measurements method, comparison of film cooling effectiveness has been made against the previous results. As the present study involved a steeper hole angle at $20^{\circ}$, a different test model have been designed for the purpose of validation. A similar test model consisting 20 cooling holes as been discussed in the previous section have been constructed with the only different is on the hole angle; at $35^{\circ}$ which commonly found in the literature the result of this test model noted as tmB; $B R=0.5$ in Figure 5. The figure shows the laterally average film cooling effectiveness measured by the present study; tmB; BR 0.5 and tmA; BR 0.5 together with the previous studies of Kohli et al. [18] and Sinha et al. [9]. Measured film cooling effectiveness in the present study compares favorably to the previous literature $[9,18]$. Although the results generally agreed to each other, larger discrepancy can be found at the location further downstream of the cooling hole. This can be explained by the existent of the second row cooling hole at $x / \mathrm{D}=10$. The existence of the cooling hole downstream in the present study, slowing down the decay of the film cooling effectiveness downstream of the hole thus high film cooling effectiveness region will be again build up after the second row holes.

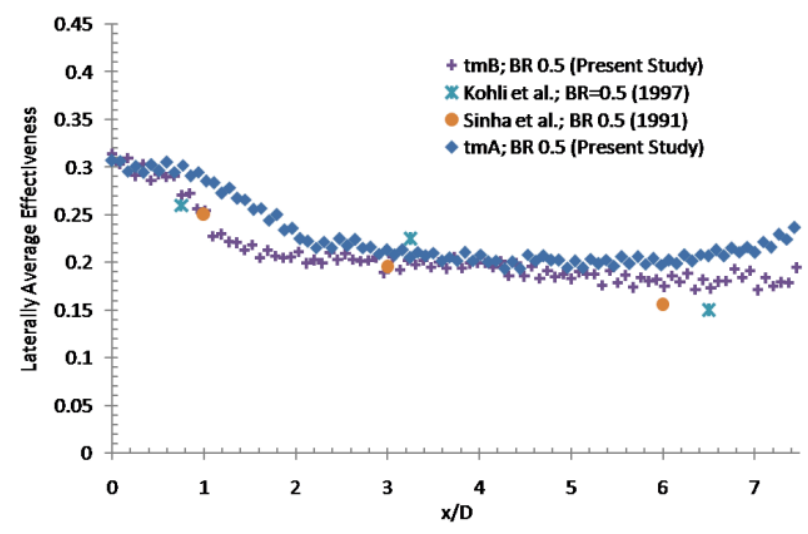

Fig. 5: Laterally Average Film Cooling Effectiveness Comparison with Previous Studies

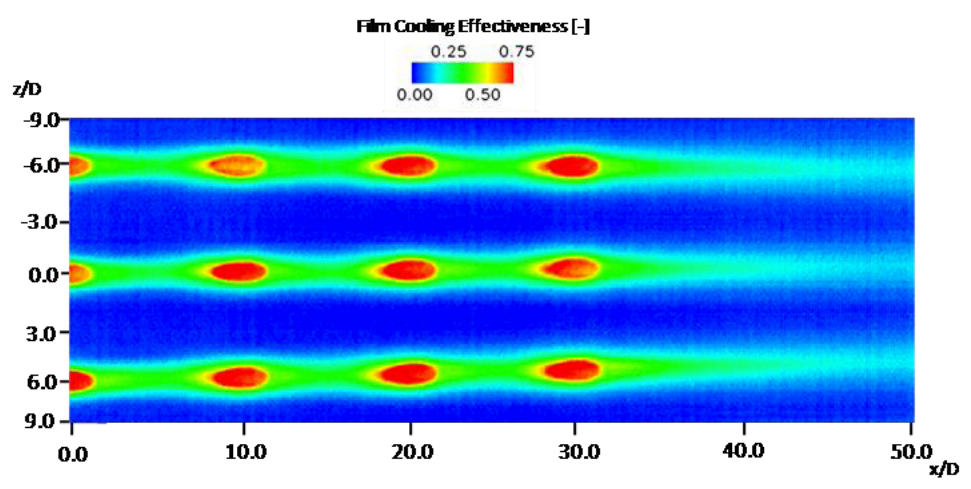

Fig. 6 Film cooling effectiveness for $\mathrm{BR}=0.5$

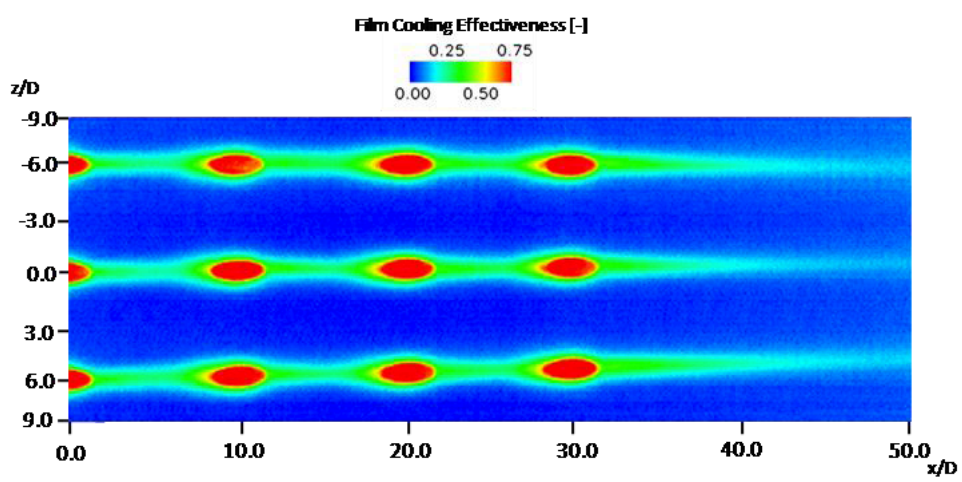

Fig. 7 Film cooling effectiveness for $\mathrm{BR}=1.0$ 


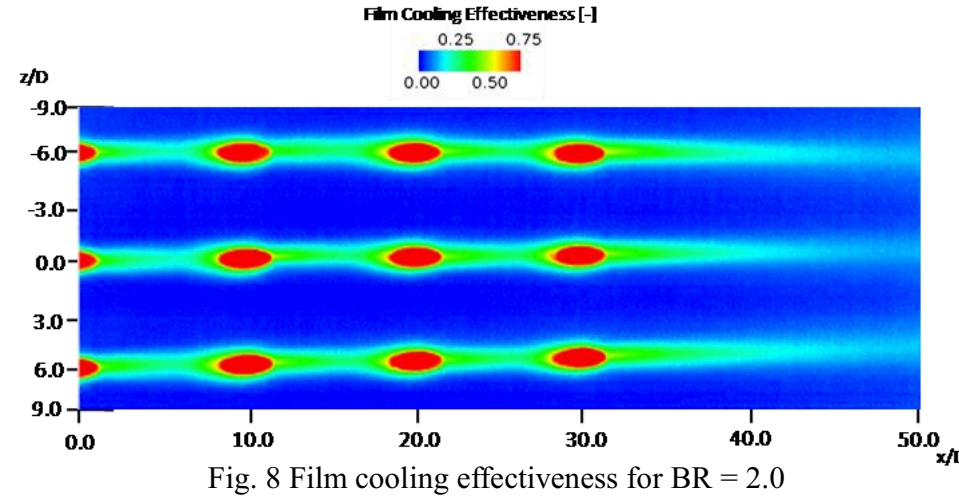

The film cooling effectiveness distribution at $\mathrm{BR}=0.5,1.0$ and 2.0 are shown in Figures 6-8 respectively. The images are scaled up to include only three holes in a row instead of the available five holes row. The overall film cooling effectiveness distribution for $\mathrm{BR}=0.5$ is clearly higher compared to the $\mathrm{BR}=1.0$ and 2.0 which is predicted and well verified by the previous researches [2-4, 7-9]. The secondary air at a lower BR will have less jet momentum compared to the higher BR thus enable the secondary air to remain attached to the surface which consequently producing a higher value of film cooling effectiveness region downstream of the cooling holes. In addition to that, the results also show a relatively high film cooling effectiveness region just downstream the holes which existent could physically interpreted as the region in which the secondary air remain attached to the surface before later on separated from the surface due to the lift-off. Drastic decline of the film cooling effectiveness further away from the holes exit can also be used as evident of the separation of the secondary air from the surface.

Although previous researches [2, 3] have suggested such region can only be found at $\mathrm{BR}=0.5$ and not at a higher $\mathrm{BR}$, the existent of it in the present study could be due to the steep inclination angle of the present study $=20^{\circ}$. As the inclination angle is steeper, the secondary jet is expected to have lower vertical component which contribute to less penetration of the secondary air into the mainstream thus remains attached to the surface even at a higher BR of the present study. The size of the region discussed above is less at the first row and expanding towards the next row and most at the last row. Such phenomenon can be explained by the cumulative effect cause by the present hole arrangement. The existent of the downstream hole rejuvenate the cooling capacity of the incoming coolant from the upperstream hole. This is also shown by the laterally average film cooling effectiveness shown in Figure 9 with slight increase of the film cooling effectiveness value can be notice from the first row to the second row, third row and the fourth row.

In terms of film cooling coverage, there are noticeable different between the tail shape of film cooling effectiveness of $B R=0.5$ to the one at $\mathrm{BR}=1.0$ and $=2.0$ downstream of the last row. The tails shape of film cooling effectiveness at lower BR become narrower just after hole exit compared to which at higher BR. The possible explanation of this, as more secondary air were supplied at higher $\mathrm{BR}$, more secondary air can be spread-out to provide more coverage of the surface downstream of the cooling hole. The laterally average film cooling effectiveness presented in Figure 9 can also be used to support such interpretation with the laterally average film cooling effectiveness value downstream of the third row hole and forth row hole of both $\mathrm{BR}=1.0$ and 2.0 is indistinguishable.

Figure 9 shows the laterally average film cooling effectiveness along the $x / \mathrm{D}$ distance. The presented average value covers of one pitch distance with the reference to the center of the hole. The red, blue and green marker represent the $\mathrm{BR}=0.5,1.0$ and 2.0 respectively. As expected, the overall laterally average film cooling effectiveness at $\mathrm{BR}=0.5$ is the highest with the value at $\mathrm{BR}=1.0$ and 2.0 diverge only at downstream of the first row and second row before become identical downstream of third row and fourth row. Weaker secondary air jet momentum enable the secondary air to remain attached to the wall after entering the mainstream thus leading to a higher film cooling performance at the $\mathrm{BR}=0.5$. The identical result of $\mathrm{BR}=1.0$ and 2.0 after the third row have been explained earlier in this section. The attachment of the secondary air on the wall at lower BR also shown by superior laterally average film cooling effectiveness value obtained just downstream of each row hole $(x / \mathrm{D}=10,20$, and 30$)$

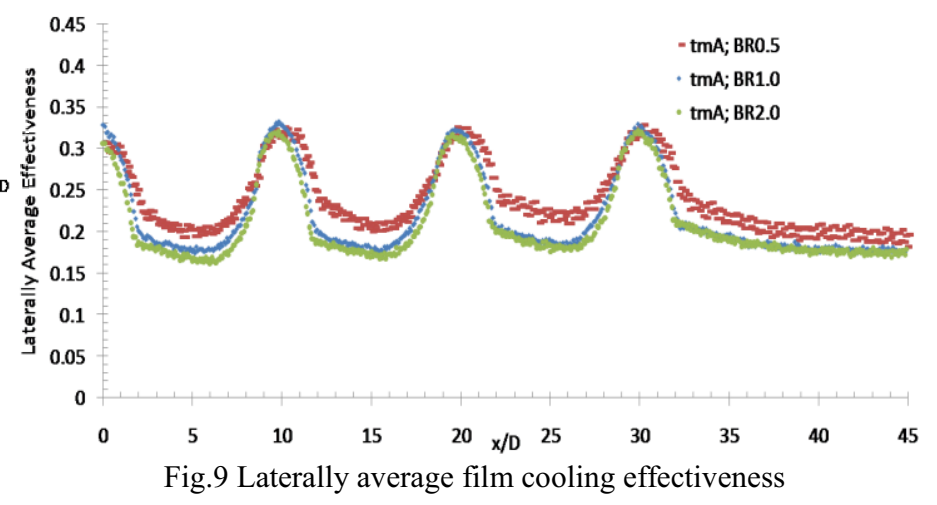

A rapid increase of the laterally average film cooling effectiveness that occurs just before the second row, third row and fourth row cooling holes could possibly indicate the existent of the cumulative effects due to the in-line holes arrangement of the present study. One should anxiously acknowledged such conclusion as the high temperature rise near the hole exit particularly at the upperstream side could possibly cause by heat conduction from the inner wall of the hole. Given the later cause, the cumulative effect could possibly do not exist. Figure 9 also shows that the laterally average film cooling at all blowing ratios experience a noticeable increase along the $x / \mathrm{D}$ hence prove the existence of the cumulative effect of the in-line hole arrangement.

\section{Aerodynamics}

Figures 10 and 11 show the normalize $u$-velocity at all measurement planes. At both BR, a high velocity region can be spotted to accommodate nearly at the same position at all measurement plane. The high velocity region for $\mathrm{BR}=1.0$ represents a high shear region cause by the blockage effects afforded by the secondary air penetration into to the mainstream. The same physical phenomenon have occurred at $\mathrm{BR}=2.0$, but in addition to the blockage effects, the high velocity region have also been contributed by the higher velocity of the secondary air exited the cooling hole as comparison to the mainstream velocity. As been mentioned in the section of heat transfer, the lift-off effect can clearly be seen for both BR cases with higher BR cause greater the lift-off effect as been shown in Figure11. The existent of the kidney vortices as been found by previous researchers can be confirmed with the plot of $v w$ vectors imbedded in Figures 10-15.

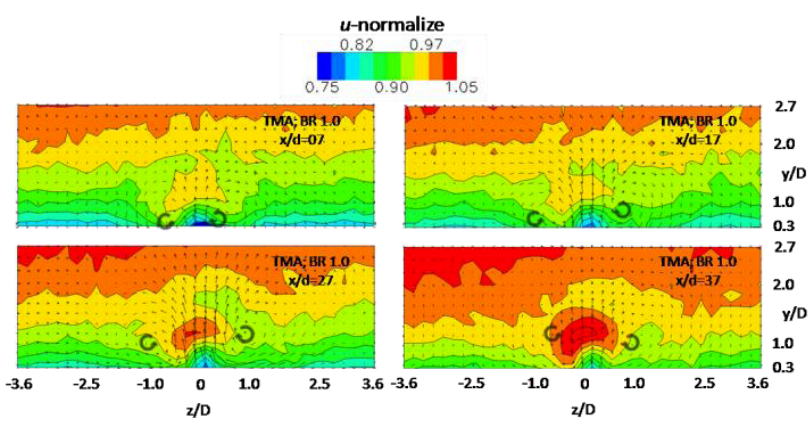

Fig. 10 Normalize $u$-velocity at $\mathrm{BR}=1.0$

Figures 11 and 12 show the normalize $v$-velocity at $\mathrm{BR}=1.0$ and 2.0 with the $v w$ vector plot. The penetration of the secondary into the mainstream can be clearly justified by the figures. The figures also indicate the existent of three different regions with a 
pair of negative velocity regions squeezing the positive velocity region at the middle. The positive region indicates the penetration of the secondary air into the mainstream meanwhile the negative regions indicates the downward movement of the air. One should notice that at $\mathrm{BR}=1.0$, plane $x / \mathrm{D}=37$, two separate regions of high $v$-velocity can be seen which are not present at other locations. The above region represent high shear layer of the cumulated secondary air of the upperstream cooling holes (first to third rows) with the below region representing the high shear layer of the respective secondary air (fourth row).

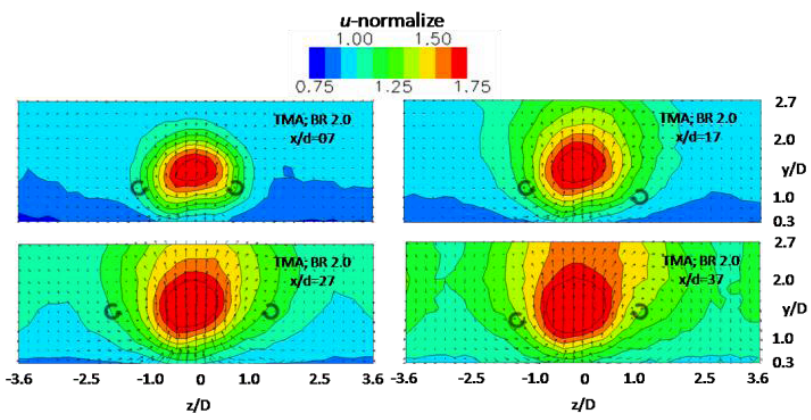

Fig. 11 Normalize $u$-velocity at $\mathrm{BR}=2.0$

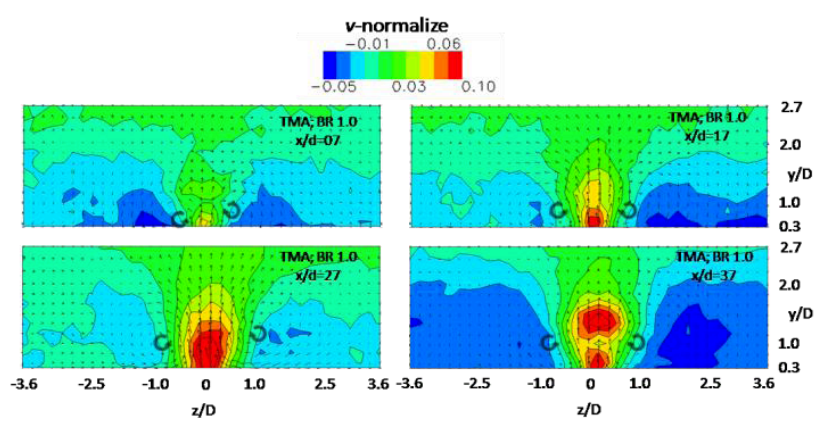

Fig. 12 Normalize v-velocity at $\mathrm{BR}=1.0$

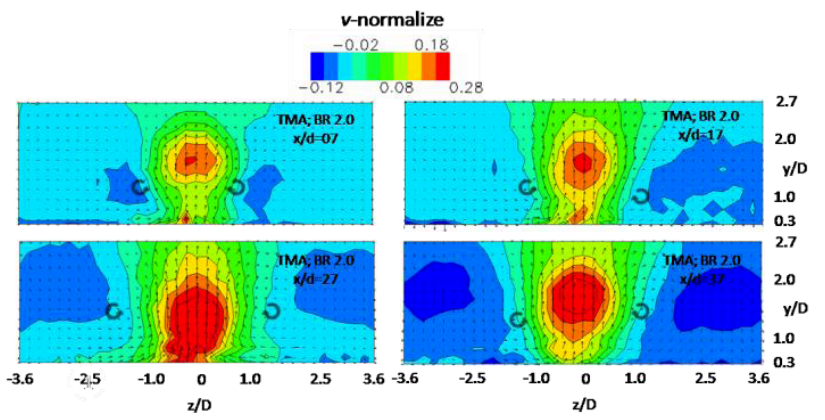

Fig.13 Normalize $v$-velocity at $\mathrm{BR}=2.0$

Figures 14 and 15 show the normalize $w$-velocity measured at all plane for $\mathrm{BR}=1.0$ and 2.0 respectively. Four significant regions can be seen from the contour with two regions represent the positive direction of $w$-velocity component and vice versa. The negative and positive regions that occur at the lower section of the measured plane represent the inward movement of the air to the centre of the plane. These regions growth as we moving downstream from $x / \mathrm{D}=$ 07 to $x / \mathrm{D}=37$ in both $\mathrm{BR}$ cases. The growth represents the strength of the kidney vortices that occur at the measured plane. As expected the size and the growth rate of these regions are superior at $\mathrm{BR}=$ 2.0 compared to $\mathrm{BR}=1.0$. Higher jet momentum at higher blowing ratio propagates the growth of the kidney vortices compared to lower BR case. From the heat transfer point of view, growth of the kidney vortices will only increase the mixing rate between secondary air and mainstream flow thus generating lower film cooling effectiveness which has been the evident as been discussed in the heat transfer section.

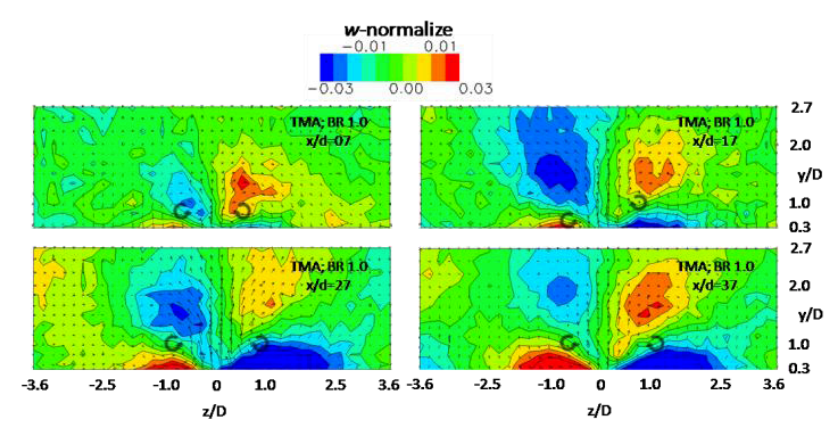

Fig. 14 Normalize $w$-velocity at $\mathrm{BR}=1.0$

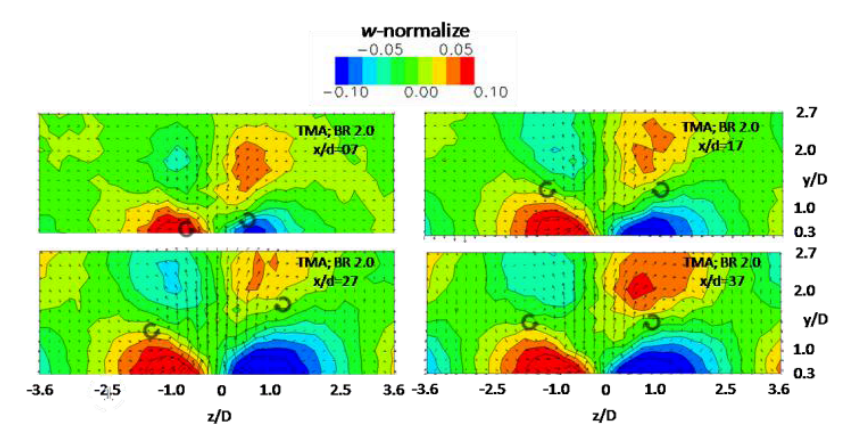

Fig. 15 Normalize $w$-velocity at $\mathrm{BR}=2.0$

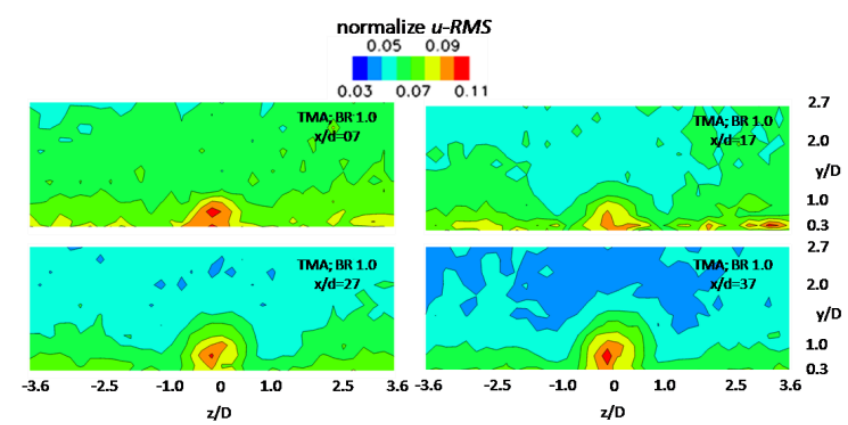

Fig. 16 Normalize $u$-RMS at $\mathrm{BR}=1.0$

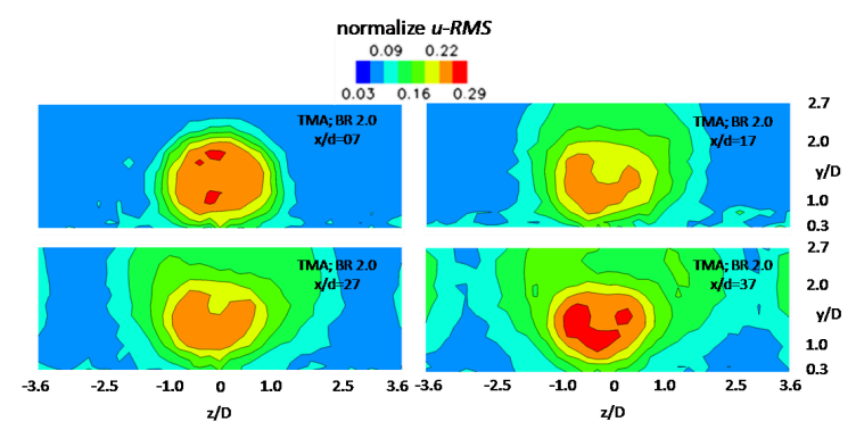

Fig. 17 Normalize $u$-RMS at $\mathrm{BR}=2.0$

Normalize $u$-RMS contour presented in Figures 16 and 17 for $\mathrm{BR}=1.0$ and 2.0 respectively. The value of $u$-RMS which is given by Eq. (3) normalize to the mainstream flow is also known as turbulent intensity level, $T u$ given in percentage. The peak turbulent intensity level for BR $=1.0$ and 2.0 was recorded at $T u=11 \%$ and $29 \%$ respectively. Both of these peak value have been found at the $\mathrm{x} / \mathrm{D}=37$ plane. It indicates that the existence of higher shear layer region in the higher blowing ratio case compared to the lower one. Comparing the location of these peak region, in $\mathrm{BR}=2.0$ the region has occurred quite further away from the wall compared to the BR $=1.0$ case. Similar to the findings of Thole et al. [12] the high Tu region found to be a just beneath of the high $u$-velocity region previously shown in Figures 10 and 11 representing the region in which the secondary air is interacting with the mainstream flow. Having the same growth pattern of $u$-RMS, the growth of $v$-RMS 
region seems to be elongated in the $y$-direction as shown in Figures 18 and 19. Direct explanation of this is that as we are moving downstream of the cooling hole the penetration of the secondary air becoming more prominent together with the new shear region created by the introduction of the secondary air into the mainstream.

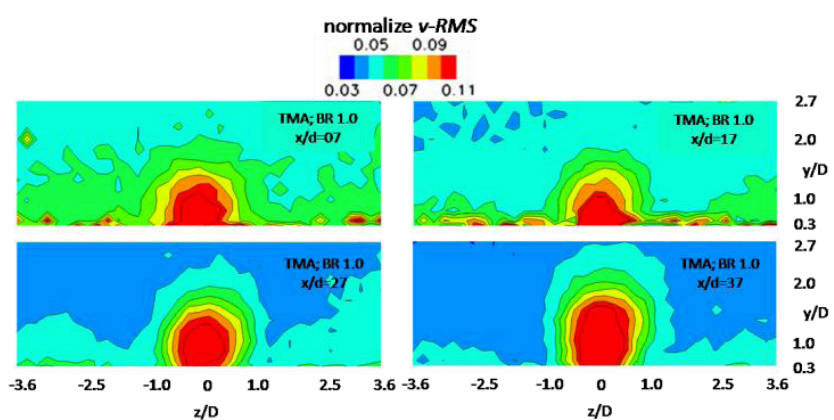

Fig. 18 Normalize $v$-RMS at $\mathrm{BR}=1.0$

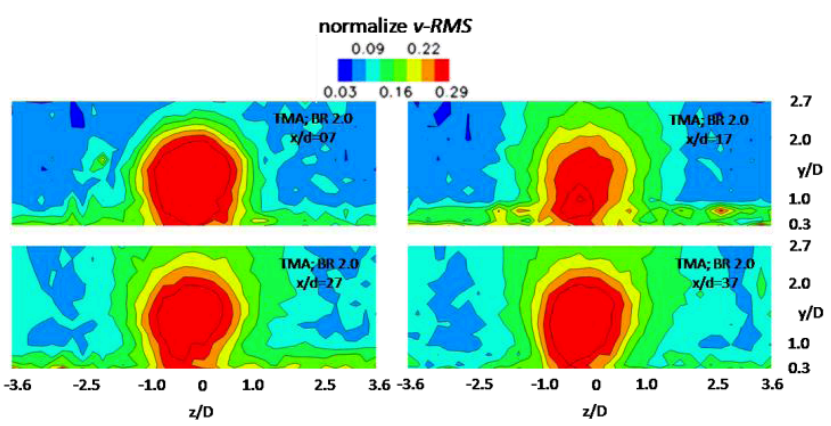

Fig. 19 Normalize $v$-RMS at $\mathrm{BR}=2.0$

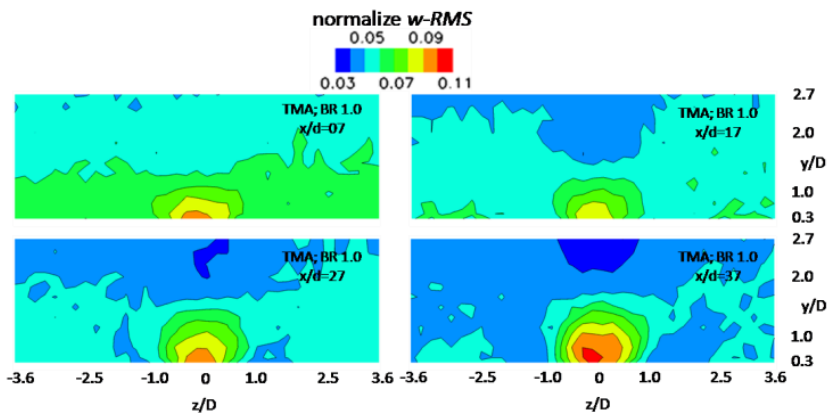

Fig. 20 Normalize $w$-RMS at $\mathrm{BR}=1.0$

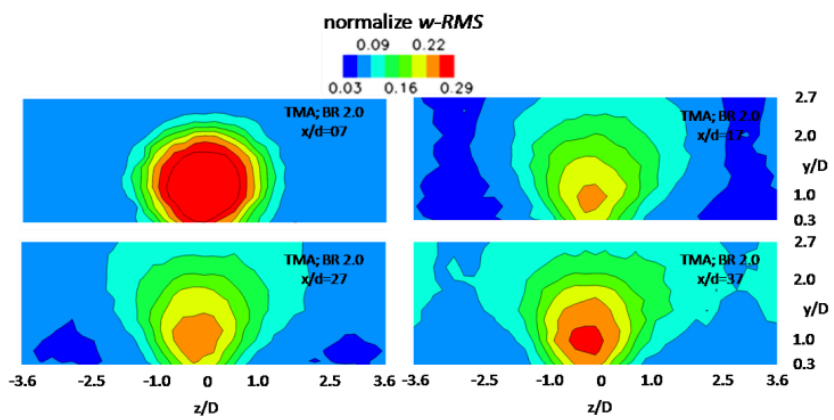

Fig. 21 Normalize $w$-RMS at $\mathrm{BR}=2.0$

Figures 20 and 21 show $T u$ level contours for $w$-velocity component. The region of high $T u$ level in all planes is located at the plane center in $z$-direction. The location of this region represents the region in which the strong positive and negative magnitude of $w$-velocity met as shown in Figures 14 and 15. The results of Figures 14 and 15 can also be used to explain the growth pattern of the high $w$-RMS. which have a mushroom growth pattern. As the opposing direction of the $w$-velocity component become more significant further downstream as shown in Figures 14 and 15 the region of high $w$-RMS also experience the same manner.

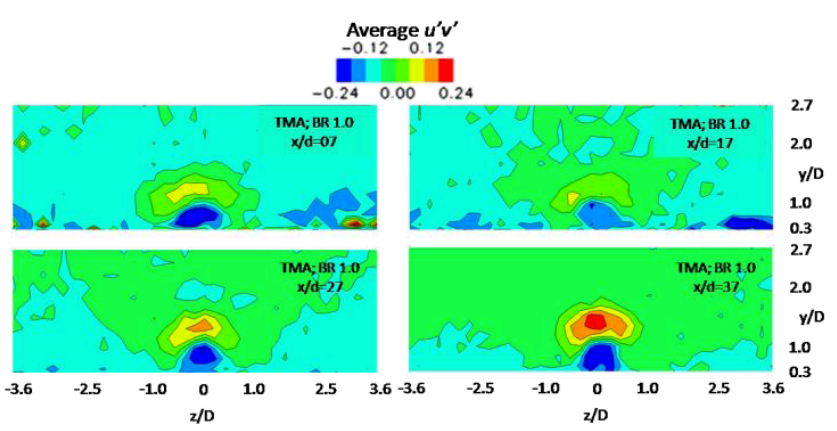

Fig. $22 \overline{u^{\prime} v^{\prime}}$ at $\mathrm{BR}=1.0$

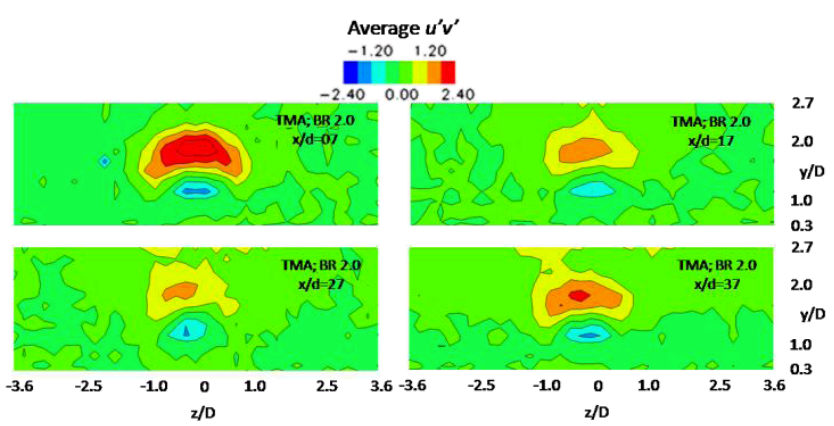

Fig. $23 \overline{u^{\prime} v^{\prime}}$ at $\mathrm{BR}=2.0$

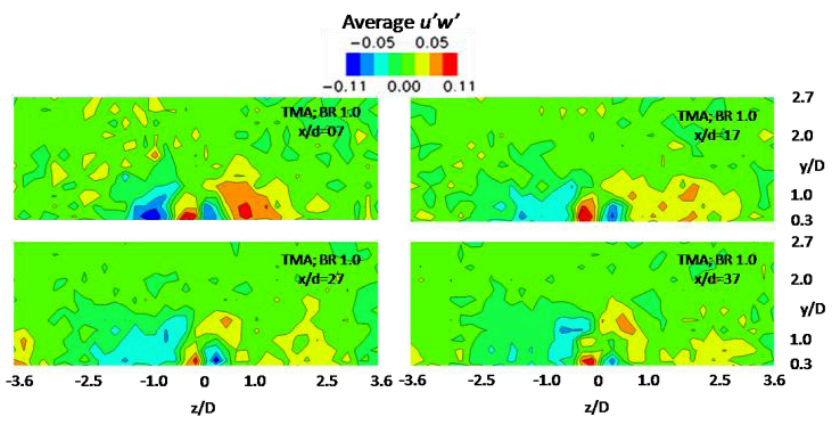

Fig. $24 \overline{u^{\prime} w^{\prime}}$ at $\mathrm{BR}=1.0$

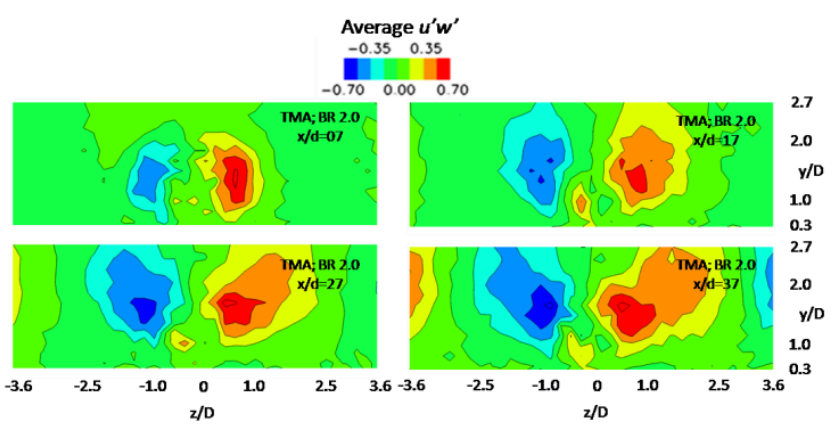

Fig. $25 \overline{u^{\prime} w^{\prime}}$ at $\mathrm{BR}=2.0$

Figures 22 and 23 show the Reynolds stress tensor of $\overline{u^{\prime} v^{\prime}}$ for $\mathrm{BR}=1.0$ and 2.0 at all considered plane. The peak magnitude of $\overline{u^{\prime} v^{\prime}}$ are 0.25 and 2.31 for $\mathrm{BR}=1.0$ and 2.0 respectively. Both of the peak points appear at two different planes; at $x / \mathrm{D}=37$ for $\mathrm{BR}=1.0$ and at $x / \mathrm{D}=07$ for $\mathrm{BR}=2.0$. Generally there are two main regions in the $\overline{u^{\prime} v^{\prime}}$ plots; negative and positive regions. The positive region appears far away from the wall while the negative region appears just beneath the positive region. The existent of such region can be confirmed by the finding of previous researches [12, 
13]. Both of the positive and negative $\overline{u^{\prime} v^{\prime}}$ are prove of existent of high shear region which indicates the interaction between the flow and the wall (negative region) also between the mainstream and the secondary air (positive region). Reynolds stress tensor of $\overline{u^{\prime} w^{\prime}}$ for $\mathrm{BR}=1.0$ and 2.0 is presented in Figures 24 and 25. Compared to $\mathrm{BR}=2.0$, there are four noticeable region in the $\overline{u^{\prime} w^{\prime}}$ plots at $\mathrm{BR}=$ 1.0 with two positive regions and vice versa. Both of the pairs can be said to have nearly the same magnitude with an opposite sign. The two positive and negative regions which occurred at the center of the plane cannot be seen instead being replaced by a single positive region at $\mathrm{BR}=2.0$. Similar to the explanation of $\overline{u^{\prime} v^{\prime}}$, the regions existent can represent the boundary in which there are significant flow interaction which in this case is between the mainstream flow and the secondary air.

\section{CONCLUSION}

Empirical studies involving heat transfer and aerodynamics of multiple cooling holes have been presented. The results shown that steeper hole angle, $\theta=20^{\circ}$ provide better film cooling effectiveness particularly just at the exit of the cooling hole compared to the commonly employed hole angle, $\theta=35^{\circ}$. The betterment of this contributed by the fact that lower vertical velocity component at steeper hole angle minimize the penetration of the secondary air thus allowing more coolant to stay attached on the surface compared to the less steep cooling hole. The results can also confirmed that the overall film cooling effectiveness is better at a lower BR compared to the higher BR as been agreed by previous researches. Higher coolant momentum at a higher BR causes a greater lift-off effect causing the coolant to be separated from the wall surfaces. This explanation can be confirmed with the aerodynamics results presented in this paper. But the effect of blowing ratio at $\mathrm{BR}=1.0$ and 2.0 show a different behavior with both blowing ratio have identical laterally average film cooling effectiveness from downstream of row three. The phenomena has been explained as, more secondary air were supplied at higher BR improve the spread of the secondary air thus providing wider coverage of the surface downstream of the cooling hole.

Evident on the existent of cumulative effects due to the in-line holes arrangement can also be confirmed by the result. Increase in the laterally average film cooling effectiveness approaching the downstream hole could possibly be interpreted as the above mention phenomenon. But such phenomenon should be further confirmed in much more accurate way given there are possibility of the high temperature region is cause by the conduction heat transfer from the inner holes wall. Another evident of the existent of the cumulative effects is the slightly higher laterally average recorded at each downstream of the row compared to the upperstream hole. Given the cooling capability of the incoming upperstream secondary air not yet totally vanished, the newly introduce coolant will have a better cooling capability from the coolant introduced by the upperstream hole.

As for the aerodynamics results, the existent of the kidney vortices downstream of the cooling hole have been successfully captured. The results have been discussed to contemplate the heat transfer results. Although most of the aerodynamics results presented in the paper have been well resolved by the computational fluid dynamics, availability of empirical data such as normalize $u$-RMS, $v$-RMS and $w$-RMS together with Reynolds stress tensor will stand as a reference in determining the accuracy of the a given CFD scheme particularly involving the transient method.

\section{REFERENCES}

[1] Goldstein, R.J., Eckert, E.R.G., Tsou, F.K., and Haji-Sheikh, A., 1971, "Film Cooling," Advances in Heat Transfer, Vol. 7, pp. 32-379.

[2] Jubran, B., and Brown, A., 1985, "Film-cooling From Two Rows of Holes Inclined in the Streamwise and Spanwise Directions," ASME J. Engineering Gas Turbines Power, Vol. 107, pp. 84-91.

[3] Goldstein, R.J., Eckert, E.G., Eriksen, V.L., and Ramsey, J.W., 1970, "Film-cooling Following Injection through Inclined Circular Tubes," Israel J. Technology, Vol. 8, pp.145-154.

[4] Schmidt, D.L., Sen, B., Bogard, D.G., 1996, "Film Cooling With Compound Angle Holes: Adiabatic Effectiveness," ASME J. Turbomachinery, Vol. 118, pp. 807-813.

[5] Ligrani, P.M., Wingle, J.M., Ceriello, S., and Jakson, S.W., 1994, "Film Cooling from Holes with Compound Angle Orientations Part 1: Results Downstream of Two Staggered Rows of Holes with 3d Spanwise Spacing," ASME J. Heat Transfer, Vol. 116, pp. 341-352.

[6] Ligrani, P.M., Wingle, M., and Jakson, S.W., 1994, "Film Cooling from Holes with Compound Angle Orientations Part 1: Results Downstream of Two Staggered Rows of Holes with 6d Spanwise Spacing," ASME J. Heat Transfer, Vol. 116, pp. 353-362.

[7] Rebekah A.R., Alfred, D., and Wright, L.M., 2009, "Measurement of Details Heat Transfer Coefficient and Film Cooling Effectiveness Distribution using PSP and TSP," Proceeding of ASME Turbo Expo, GT2009-59975

[8] Cho, H.H., Rhee, D.H., and Kim, B.G., 2001, "Enhancement of Film-cooling Performance Using a Shaped Film-cooling Hole with Compound Angle Injection," JSME International Journal, Series B, Vol. 44, No. 1, pp. 99-110.

[9] Sinha, A.K., Bogard, D.G., Crawford, M.E., 1991, "FilmCooling Effectiveness Downstream of a Single Row of Holes with Variable Density Ratio," ASME J. Turbomachinery, Vol. 113, pp. 442-449.

[10] Andreopoulus, J., and Rodi, W., 1984, "Experimental Investigation of Jets in a Crossflow," J. Fluid Mechanics, Vol. 138, pp. 93-127.

[11] Subramaniam, C.S., Ligrani, P.M., Green, J.G., Doner, W.D., and Kaisuwan, P., 1992, "Development and Structure of a Film-Cooling Jet in a Turbulent Boundary Layer with Heat Transfer," Proceeding of the $3^{\text {rd }}$ International Symposium on Transport Phenomena and Dynamics of Rotating Machinery, pp. 53-68.

[12] Pietrzyk, J.R., Bogard, D.G, and Crawford, M.E., 1989, "Hydrodynamic Measurements of Jets in Crossflow for Gas Turbine Film Cooling Application," ASME J. Turbomachinery, Vol. 111, pp. 139-145.

[13] Thole, K., Gritsch, M., Schulz, A., and Wittig, S., 1996, "Flowfield Measurements for Film-Cooling Holes with Expanded Exits," Proceeding of International Gas Turbine and Aeroengine Congress and Exhibition, 96-GT-174.

[14] Gritsch, M., Schultz, A., and Witting, S., 1998, "Adiabatic Wall Effectiveness Measurements of Film-Cooling Holes with Expanded Exit," ASME J. Turbomachinery, Vol. 120, pp. 549-556.

[15] Wrigth, L.M., McClain, S.T., and Clemenson, M.D., 2010, "Effect of Freestream Turbulent Intensity on Film Cooling Jet Structure and Surface Effectiveness Using PIV and PSP," Proceeding of ASME Turbo Expo, GT2010-2354.

[16] Kampe, T., Volker, S., Haneka, C., Ladisch, H., Schulz, A., and Bauer, H.J., 2011, "Experimental and Numerical Investigation of Flow Field and Downstream Surface Temperatures of Cylindrical and Diffuser Shaped Film Cooling Holes," Proceeding of ASME Turbo Expo, GT2011-45106.

[17] Ekkad, S.V., Heidmann, J., Dhungel, A., Lu, Y., and Wynn P., 2009,"Film Cooling From a Row of Holes Supplemented with Antivortex Holes," ASME J. Turbomachinery, Vol. 131, pp. 021007-10.

[18] Kohli, A., and Bogard, D.G., 1997, “Adiabatic Effectiveness, Thermal Fields, and Velocity Fields for Film Cooling with Large Angle Injection," ASME J. Turbomachinery, Vol.119, pp. 352-358. 